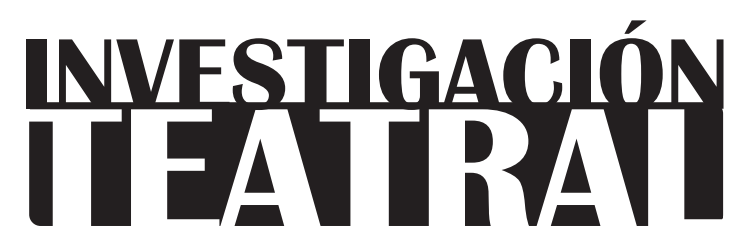

Revista de artes escénicas y performatividad

Vol. 9, Núm. 13

abril-septiembre 2018

Segunda época

ISSN impreso: 1665-8728

ISSN electrónico: 2594-0953

Universidad Veracruzana

\title{
Cuerpo estigmatizado y enunciación paratópica en la performance de Lechedevirgen Trimegisto
}

Antoine Rodríguez*

* Centre d'Etudes en Civilisations, Langues, et Lettres Etrangères, Universidad de Lille, Francia.

e-mail: antrodriguez52@gmail.com

Recibido: 30 de agosto de 2017

Aceptado: 28 de enero de 2018 


\title{
Cuerpo estigmatizado y enunciación paratópica en la performance de Lechedevirgen Trimegisto
}

\section{Resumen}

Este trabajo propone un análisis de la performance Pensamiento Puñal (2012) del artista mexicano Felipe Osornio "Lechedevirgen Trimegisto", tomando como punto de partida la noción de paratopía teorizada por el lingüista francés Dominique Maingueneau. Se reflexiona sobre varios aspectos de la creación de Lechedevirgen Trimegisto: la escenificación de la postura paratópica del creador —es decir, de su problemática inserción en el espacio sociocultural-, las filiaciones culturales que sirven de legitimación a la obra y la des-biopolitización del cuerpo masculino cuir/queer a la que se dedica el artista de performance.

Palabras clave: performance, paratopía, cuerpo, masculinidad, queer, México.

\section{Stigmatized Body and Paratopic Enunciation in the Performance of Lechedevirgen Trimegisto}

\begin{abstract}
This article discusses the performance Pensamiento Puñal (2012) of Mexican artist Felipe Osornio (a.k.a. Lechedevirgen Trimegisto), taking cue from the notion of paratopia, as theorized by the French linguist Dominique Maingueneau. Several aspects of Lechedevirgen Trimegisto's work are addressed: the staging of the artist's paratopic positioning (that is, of the problematic way in which he locates himself in the socio-cultural space), the cultural affiliations that serve as legitimation to his work, and the des-biopoliticization of the queer male body.
\end{abstract}

Keywords: performance, paratopia, body, masculinity, queer, Mexico. 


\section{Cuerpo estigmatizado y enunciación paratópica en la performance de Lechedevirgen Trimegisto}

$\mathrm{E}$ ncerrado en una habitación, con el cuerpo enfermo recuperándose de un herpes zóster que lo dejó inmovilizado varias semanas, Felipe Osornio (n. 1991) escribe, desde el dolor - "entre vómitos, sangrados nasales y mucho dolor" ("Pensamiento puñal, crítica", entrevista) - "Pensamiento Puñal", un texto poético-mágico que puede considerarse como una especie de manifiesto en el que Lechedevirgen Trimegisto (nombre artístico de Osornio) parece asentar las bases o líneas que van a orientar su obra performática. En dicho texto - escrito en noviembre de 2012, cuando Osornio tenía 21 años- el cuerpo estigmatizado, ${ }^{1}$ herido, adolorido, va a convertirse en herramienta epistemológica de resistencia política.

Una advertencia agregada por el autor al final del mismo, precisa: "Esto no es una 'Receta Política', se trata de un ejemplo acerca de cómo construir un pensamiento crítico y reflexivo. Esto no es una categoría sino un espacio de acción creativa y pánica. ${ }^{2}$ No po-

1 Entiendo la palabra "estigma" en el sentido que le da el sociólogo Erving Goffman (Stigmate), es decir, un atributo que desacredita profunda y socialmente a una persona. Hay tres tipos de estigmas. El primero tiene que ver con "la monstruosidad" o "deformidad" del cuerpo. El segundo se relaciona con lo que los otros perciben como "taras de carácter" ("falta de voluntad", "pasiones irreprimibles o antinaturales"). En cuanto al tercero, agrupa los estigmas "tribales" (raza, nacionalidad, religión) (13-14). Traducción mía, del francés.

2 Se refiere seguramente al Teatro Pánico, movimiento artístico fundado por el dramaturgo español Fernando Arrabal a principios de los años 1960. El Teatro Pánico también se basó en una especie de manifiesto, bajo la forma de una conferencia en la que Arrabal abogaba por un arte regido por una locura controlada frente a una sociedad en crisis de valores. 
drás devenir Puñal, pero sí podrás aPUÑALar el sistema" (Lechedevirgen, "Pensamiento Puñal" 20). La intención programática del texto es evidente: se trata de "construir" un cuestionamiento epistemológico ("un pensamiento crítico") en el marco de la creación artística del autor que se concreta en su elaboración performática (en el sentido de arte acción) y producir nuevos conocimientos sobre el cuerpo y la masculinidad. También es evidente la dimensión política: "apuñalar" metafóricamente "al sistema", significa deconstruir de manera radical las redes normativas de un poder hegemónico, o dicho de otra manera, cuestionar el carácter naturalizado de dichas normas explicitando su construcción y función culturales.

En el marco de este trabajo tomaré como punto de partida el texto "Pensamiento Puñal", que sirvió de base a la performance homónima del propio Lechedevirgen. ${ }^{3} \mathrm{Mi}$ propósito es reflexionar sobre varios aspectos de la creación de Osornio: la escenificación de la postura paratópica del creador (es decir, de su problemática inserción en el espacio sociocultural), las filiaciones culturales que sirven de legitimación a la obra y la des-biopolitización del cuerpo masculino a la que se dedica el performancero.

\section{Crear (desde) la paratopía}

En 2004, el lingüista francés Dominique Maingueneau publica un libro sobre discurso literario: Le discours littéraire: Paratopie et scène d'énonciation, en el que teoriza la noción de "paratopía", concepto que él mismo crea para dar cuenta de los procesos complejos que posibilitan y legitiman la emergencia de la creación de una obra literaria y su inserción en el campo literario. Pero además de su aplicación en el campo literario, el concepto se puede extender a cualquier proceso creativo y particularmente a la propuesta performática de Lechedevirgen que, en el caso de Pensamiento Puñal, se fundamenta justamente con la elaboración de un texto literario cuya función es ser objeto de una realización de arte acción.

La paratopía es la paradójica situación del escritor que no puede situarse al exterior de la sociedad ni tampoco en el interior de la misma (Maingueneau, Le discours littéraire 52), quedando condenado a elaborar su obra a partir del carácter radicalmente problemático de su propia pertenencia a la sociedad. Su enunciación se constituye a través de tal imposibilidad de asignarse un verdadero lugar. La paratopía es entonces una localización para-

3 Este texto también fue utilizado por el performer mexicano Lukas Avendaño en su acción titulada Crimen organizado, que pude ver en el marco del Primer Foro de Teoría Queer de la Universidad Veracruzana (7 de noviembre de 2013). 
dójica: no es ausencia de lugar, sino una difícil negociación entre el lugar y el no-lugar, una localización parasitaria (ibid.). No se trata, como en el caso de la "heterotopía" foucaultiana (Foucault, "Des espaces autres") de una representación o de una subversión de un espacio real que admitiría la superposición de varios espacios incompatibles (como el cine, el teatro o el cementerio, según los ejemplos que da Michel Foucault), sino de posibilitar, en el marco del acto creativo, una ubicación dentro de un espacio determinado del que el artista queda, no obstante, excluido.

El artista es a la vez el impuro (el "inmundo", fuera del mundo) y la fuente de todo valor; el paria y el genio, según la ambivalencia del término latín sacer, maldito y sagrado (Maingueneau, Le discours littéraire 78). La paratopía es un proceso que sólo se puede considerar a través de su enunciación discursiva; no hay, precisa Maingueneau, situación paratópica extra-literaria. Es, a la vez, aquello de lo que hay que liberarse a través de la creación y aquello que la creación ha de elaborar; lo que da la posibilidad de acceder a un lugar y lo que prohíbe toda pertenencia espacial (Maingueneau, "Quelques implications"). A través de su obra y en un mismo movimiento, el escritor debe resolver y preservar una imposible pertenencia. Crear significa producir una obra y construir al mismo tiempo las condiciones que permitan producirla. Toda paratopía significa, por lo menos, la pertenencia y la no-pertenencia, la imposible inclusión en un lugar (topos). La paratopía aleja ya sea de un grupo (paratopía de identidad), de una ubicación (paratopía espacial) o de un momento (paratopía temporal).

La paratopía de identidad (familiar, sexual o social) ofrece todas las figuras de la disidencia y la marginalidad, literal o metafórica: "mi grupo no es mi grupo". De cierta manera, y particularmente en el caso de producciones de artistas pertenecientes a minorías sociales, sexuales o étnicas (como es el caso de Lechedevirgen), hay una posible articulación entre el concepto de paratopía y el de "desidentificación”, teorizado por el crítico cubano-estadounidense José Esteban Muñoz (desidentification) y aplicado también al análisis de performances latinoamericanas queer. Partiendo de los aportes teóricos del lingüista francés Michel Pêcheux, Muñoz concibe el concepto de "desidentificación" como una manera de:

describir las estrategias de supervivencia que pone en práctica el sujeto que pertenece a una minoría con el fin de negociar con una esfera fóbica mayoritaria que todo el tiempo acalla o castiga la existencia de sujetos que no se ajustan al espectro de la ciudadanía normativa ("Introducción a la teoría” 557).

La desidentificación es, pues, una manera de negociar (o de jugar) con(tra) la ideología dominante. Consiste en negarse a asimilar dicha ideología sin tampoco rechazarla totalmen- 
te, o "reciclar y repensar un significado codificado" que permita, a partir de los elementos de la codificación hegemónica, "representar una política o postura, privada de su fuerza, que la cultura dominante convirtió en algo impensable" (595). La desidentificación es un proceso paratópico en la medida en que supone una identificación parcial y atípica con los códigos dominantes, por ejemplo cuando un varón homosexual se identifica, no con un varón masculino, sino con una estrella de cine femenina.

Por su parte, la paratopía espacial es la de los exilios ("mi lugar no es mi lugar”, "en cualquier lugar donde esté, no estoy en mi lugar”), mientras que la paratopía temporal se fundamenta en el anacronismo: "mi tiempo no es mi tiempo", ya sea en el modo del arcaísmo o de la anticipación: se es sobreviviente de una época pasada o ciudadano prematuro de un mundo venidero (Maingueneau, Le discours littéraire 86-87).

La situación paratópica de Lechedevirgen se enuncia y se escenifica desde el principio de "Pensamiento Puñal":

Escribo desde el filo de la tierra, desde el fin del mundo, el borderline de los últimos tiempos.

Desde las heridas, desde las grietas, las cortaduras de un imperio fracasado, desde el espacio místico y ambiguo del cuartomundo, desde el cut-up intertextual de las postidentidades, porque ahora que me lees, esto soy: texto.

Escribo para aquellxs que son el target, [...] subordinadxs a los márgenes, teniendo terror a los baños del colegio [...].

Para aquellxs que dar en el blanco significa una amenaza irónica, pues son de todos los colores menos el blanco. Cuerpos ocupados, desde la sala de operaciones abstracta, en el parto, líquido amniótico y sangre de madre, hasta el paredón, el ghetto, la cárcel, el hospital, apedreadxs, insultadxs, escupidxs, rechazadxs: impotentes.

Para aquellxs que un mal día se dieron cuenta que llevan cara de indio, tez de estiércol, lxs que odiaron su cuerpo, para lxs pocohombres, lxs mariachis, lxs que constituyen un atentado a la masculinidad hegemónica, directa o indirectamente, lxs que son culpables de lo que no cometieron, culpables de llevar el pecado en la carne y vivir la penitencia. (Lechedevirgen, "Pensamiento Puñal" 14)

Palabras y expresiones como "el filo de la tierra", "desde el fin del mundo", "borderline”, "últimos tiempos", "subordinadxs a los márgenes", "paredón", "ghetto" y "cárcel” van configurando un campo léxico de lo periférico y de la exclusión, un paradigma semántico que señala, entre otras cosas, una problemática inclusión en la sociedad. A la paratopía espacial se superpone la paratopía de identidad, es decir, el hecho de ser rechazado por tener como estigma corporal "cara de indio", "tez de estiércol". Es, paradójicamente, a partir de esa mis- 
ma situación de exclusión enunciada como tal, que Lechedevirgen inscribe su obra en el campo cultural de la creación performática. La exclusión funciona como la condición de su inclusión en el campo cultural, pero sólo puede incluirse enunciando su situación paratópica de marginado social.

Para enunciar la paradójica inscripción de su obra, cada autor recurre, según Maingueneau (Le discours littéraire 95-96), a toda una gama de shifters paratópicos ${ }^{4}$ (embrayages en francés, deícticos en español), tales como el bohemio, el nómada, el vagabundo, la cárcel, el sanatorio, etcétera. En el texto de Lechedevirgen son varias las figuras que funcionan como tales shifters. A modo de ejemplo citaré unas cuantas: "lxs prostitutxs", "lxs desobedientes", "lxs esclavos a distancia", "lxs delincuentes", "lxs criminales", "niñxs chicleros", "putitos", "vestidas", “chichifos", “mariquitas", “jotas", “locas", “mayatones”, “machorras", “tortilleras”, "traileras", "operadas". Toda una lista de personajes que encarnan la marginación social por su condición socioeconómica, su disidencia frente a las normas sexuales hegemónicas o bien frente a las normas sociojurídicas. Personajes que se sitúan en la periferia de la vida social, pero a los que la obra de Lechedevirgen atribuye un lugar central. Entre ellos se halla la figura proteica y simbólica del "Puñal", cuyos contornos definitorios ocupan la mayor parte del texto.

La elección de la imagen del puñal se debe a su doble sentido: un sentido denotado, que remite al objeto que corta, y otro connotado, sinónimo despectivo de homosexual, que se relaciona en el imaginario popular mexicano con la idea de traición/transgresión, con el apuñalar/penetrar por la espalda. Pero en el texto, "puñal" - y el verbo correspondiente, "apuñalar" - se convierten sobre todo en herramienta o metodología epistemológica para cuestionar la producción coercitiva de la masculinidad hetero e incluso homonormada.

Si la escritura de "Pensamiento Puñal" se lleva a cabo, como Lechedevirgen lo ha precisado en varias entrevistas, ${ }^{5}$ en el encierro y la inmovilidad del cuerpo enfermo, su génesis parte de un fracaso social que se remonta a la niñez del autor y que se asocia a un fenotipo de "indio", conjugado con la imposibilidad de adecuarse a las normas de la masculinidad viril heteronormada:

4 Maigueneau parte de la definición lingüística de "shifter": "elemento que inscribe en el enunciado su relación con su situación de enunciación". En el caso del "shifter paratópico", se trata de elementos que participan a la vez del mundo representado por la obra y de la situación a través de la cual se instituye el autor que construye el mundo representado. Un ejemplo puede ser el submarino Nautilus de la novela de Jules Vernes Veinte mil leguas de viaje submarino, que constituye una cabina paratópica nómada y que revela una imposible inscripción espacial fija. Ver Maingueneau, Le discours littéraire 96.

5 Esto se ve, por ejemplo, en la entrevista titulada "Pensamiento puñal, crítica directa a las 'coreografías' sociales", publicada en La Jornada Jalisco. 
Tengo el cuerpo demonizado, encarno el fenotipo latino del delincuente, del coyote, del sicario, del traficante, del brasero [sic] [...], del judas, del traidor, del chamuco, incluso del sex simbol (Lechedevirgen, "Pensamiento Puñal" 16).

Soy Puñal [...] por ir en contra de la ley natural, del orden social y las buenas costumbres, por penetrarles el culo hasta que sangran. Por ser abyecto, por traicionar a mi patria, a mi gobierno, a los deseos de mi madre y mi padre, a la biología y la genética, a la academia y las pinches "Bellas Artes", al racismo, al clasismo y al sexismo, por decirle NO a ser un Macho (17).

El visible estigma del fenotipo indígena - que tiende a ser interpretado como señal de inferioridad social por las clases altas y medias mexicanas-, así como la debilidad y enfermad del cuerpo, una identidad no heterosexual y la doble disidencia frente a la masculinidad hegemónica y ante una homonormatividad gay, son los elementos paratópicos a partir de cuya enunciación y puesta en escena Lechedevirgen hace obra. Ahora bien, si por un lado su inclusión en el espacio sociocultural es posibilitada, como ya señalamos más arriba, a partir de la puesta en discurso de la exclusión, son otros, en cambio, los procesos que la legitiman. Por ejemplo, las diferentes filiaciones o inscripciones genealógicas que el autor selecciona en el archivo cultural "autorizado", es decir, productor de legitimación.

\section{Crear (desde) la filiación cultural}

El texto de Lechedevirgen convoca a toda una red cultural en la que convergen artistas e intelectuales canonizados o institucionalizados, así como figuras de la cultura de masas y de la cultura popular, con los que el autor establece una filiación explícita. Fuente de inspiración, marco teórico y estético, estrategia legitimadora de la obra, dicha red se constituye a través de una selección en el archivo cultural nacional e internacional. Conecta al artista con campos como los estudios queer/cuir, el feminismo chicano, el postporno, ${ }^{6}$ el arte contemporáneo, el teatro pánico, el surrealismo, el cine nacional que el autor maneja desde lo kitsch, la performance latinoamericana, etcétera. Los extractos siguientes precisan algunos de los nombres de estos artistas o movimientos estéticos:

${ }^{6}$ Según Beatriz Preciado, la pospornografía es "el proceso de devenir sujeto de aquellos cuerpos que hasta ahora solo habían podido ser objetos abyectos de la representación pornográfica: las mujeres, las minorías sexuales, los cuerpos no-blancos, los transexuales, intersexuales y transgénero, los cuerpos deformes o discapacitados. Es un proceso de empoderamiento y de reapropiación de la representación sexual" ("Entrevista con Beatriz Preciado", parr. 1). 
[Escribo] para lxs que quieren hacer una obra maestra, morir como Ana Mendieta, Unica Zürn o Fred Herko, saltar en el vacío (14).

Soy Puñal de colección, espécimen regional heredero de Chela Sandoval, de Jodorowsky de Arrabal y Topor, del Pánico, de Anzaldúa, de Melquiades, de Mago Melchor, de Gómez Peña, de la Congelada, de Paco X., de Giuseppe Campuzano, de Gurrola, de Semefo, de Polvo de Gallina Negra, entre muchxs otros. Heredero de la genética de Cantinflas, de Tin tán [sic], de Mago Septién, de Ramón Valdez y el profesor Jirafas, de Chinchín el tepor8 y Gabriel Retes, de los bultos en los pantalones ajustados de Pedro Infante y Jorge Negrete en plena movida cruising, de Agustín Lara y sus "dos puñales" de hoja dama-esquina-mezquina, de Macario y su pacto con la muerte a través de un pollo rostizado (16).

Por otra parte, y fuera de este texto-manifiesto, Lechedevirgen ha dado varias entrevistas (algunas de ellas grabadas y disponibles en internet, otras publicadas en revistas o periódicos electrónicos) en las que precisa sus diferentes filiaciones y herencias estético-teóricas. A los nombres citados en su texto, se pueden añadir los de Julia Kristeva y su teoría sobre la abyección, Teresa de Lauretis y sus aportes teóricos sobre lo queer, Paul B. Preciado (antes Beatriz Preciado) y su teoría sobre (trans)sexualidades. Las palabras recurrentes con las que Lechedevirgen define su práctica artística son: "Performance queer [o cuir] ${ }^{7}$ extrema”, "postporno", "arte contemporáneo", "arte extremo", "arte acción”. También insiste en la conexión de su obra con la alquimia, vista ésta como un proceso de transformación de la materia y el espíritu. La elección del nombre "Trimegisto" está directamente inspirada en la alquimia y viene a simbolizar un arte cuya función es la transformación del yo y del entorno (ToutVaBien TV, "Leche de virgen Trimegisto").

La inflación discursiva - a la que el mismo autor contribuye- en torno a los aspectos definitorios de su obra performática, contrasta con el rechazo radical de toda identidad respecto al género y al sexo. Lechedevirgen se inscribe en las teorizaciones queer (o cuir, según la reapropiación del concepto por cierta crítica latinoamericana $)^{8}$ de las post-identidades y de la deconstrucción de los binarismos sexo-genéricos. "Las identidades sexuales funcionan como camisa de fuerza", dice en una conversación ("Entrevista en compañía de Felipe Osornio"); para él son como "jaulas" en las que no sólo han metido a la gente, sino que la gente se ha me-

7 Como cito las palabras de un video, no sé si cuando Lechedevirgen dice "cuir", lo conceptualiza con la grafía "queer" o "cuir".

${ }^{8}$ Para más amplia información sobre la adopción del término cuir en vez de queer, y los debates a los que dio lugar en la crítica latinoamericana, ver el libro de Fernando R. Lanuza y Raúl M. Carrasco, Queer E Cuir. Políticas de lo irreal, 2015. 
tido sin darse verdaderamente cuenta de ello. La elaboración performática de Lechedevirgen parece hallarse en una situación paradójica en la que la deconstrucción de las identidades hegemónicas respecto a los cuerpos sexuados, pasa por una fuerte filiación identitaria a discursos autorizados que lo legitiman como portador de una contestación anti-identitaria.

Definirse contra la identidad, excluyendo toda definición, pero al mismo tiempo multiplicando las identidades disidentes y socialmente estigmatizadas, parece ser otro más de los rasgos paratópicos con los que Osornio hace obra.

\section{Des-biopolitizar el cuerpo masculino}

Uno de los logros de la modernidad y del capitalismo ha sido, como lo demuestra Foucault en la Historia de la sexualidad (1976), desarrollar dispositivos para ejercer un control disciplinario de los cuerpos y la sexualidad. El bio-poder, es decir, la politización de la "nuda vida" - término que utiliza Agamben en Homo sacer para referirse a los cuerpos vivientes-, ha tenido la capacidad y la función de crear cuerpos políticamente dóciles recurriendo a toda una serie de "tecnologías adecuadas" (Agamben 12). Uno de esos dispositivos es el sistema sexo/género (Rubin, "Léconomie"), responsable de una dominación masculina que se manifiesta socialmente ya no sólo a través de la docilidad de los cuerpos, sino mediante la opresión contra las mujeres, la misoginia, la violencia contra los homosexuales y contra todo cuerpo transgresor de las normas sociales del género.

El corpus performático de Lechedevirgen gravita predominantemente sobre la formación y los efectos de la masculinidad mexicana hegemónica. Violencia de género, machismo, misoginia, homofobia, así como nacionalismo coercitivo, racismo y clasismo, son los temas que el artista escenifica para deconstruirlos. Dicha deconstrucción, que hay que entender como un cuestionamiento a la naturalización coercitiva de normas culturalmente construidas, se concreta en el espacio performático por toda una serie de combinaciones metafóricas de objetos (la introducción de un puñal en el ano, quemaduras de cigarro, agujas clavadas en la piel de la frente, entre otras) que abordaremos fugazmente más adelante. El artista pone en juego y arriesga su propio cuerpo, un cuerpo mestizo, "aindiado", que acarrea físicamente los estigmas de una nacionalidad y una masculinidad de segunda clase. Un cuerpo que, por exhibir su exclusión del marco normativo de la masculinidad hegemónica, es percibido e interpretado - según las normas de la masculinidad mexicana dominante, basada en la figura del macho- como el cuerpo de un hombre fallido. Como apunta el investigador Antonio Prieto Stambaugh ("Corporalidades políticas"), desde la década de 1990 el cuerpo se convierte en un espacio textual, "una piel transformada en pergamino diseminador de interrogantes" (609), que lleva los signos materiales del ejercicio violento del poder, la colonización y/o el color 
de una pertenencia étnica despreciada. El performer Guillermo Gómez-Peña lo expresaba así: "Nuestra principal obra de arte es nuestro propio cuerpo, impregnado de implicaciones semióticas, políticas, etnográficas, cartográficas y mitológicas" (495). Él plantea que los cuerpos de las minorías sexo-étnicas-sociales son "territorios ocupados", que el performance es capaz de someter a un proceso de descolonización (498).

De manera menos frecuente, el cuestionamiento de Lechedevirgen se vuelca también sobe la normatividad de los hombres gay: masculinos, consumistas, normatividad percibida igualmente como generadora de exclusión y violencia simbólica. Como señala Prieto Stambaugh, este artista celebra "lo cuir no desde una idealización color de rosa que domestica la diferencia, sino desplegando cuerpos performáticos de a-normalidad des-generada" ("El eros politizado" 37).

Si partimos de la premisa según la cual la configuración y los efectos de una masculinidad mexicana dominante, misógina, homofóbica y altamente violenta ha sido incorporada, voluntaria o involuntariamente, por la mayoría de los hombres a través de un proceso de biopolitización de sus cuerpos - es decir, a través de tecnologías de subjetivación y de socialización institucionalizadas como las de la familia, la escuela o la iglesia-, entonces podemos considerar que la deconstrucción a la que se dedica Lechedevirgen consiste en des-biopolitizar el cuerpo masculino, valiéndose para ello de diversos recursos textuales y escénicos.

\section{Crear (desde) el texto}

El contenido textual de "Pensamiento Puñal" hace explícitos los efectos violentos y naturalizados del sistema sexo/género (o patriarcado) a través de un lenguaje que combina abstracciones, insultos y metáforas:

[...] el régimen de mierda de dominación patriarcal occidentalista del hombre blanco, rico y heteronormativo (16).

[Soy Puñal] por no ser un "hombre hecho y derecho", por no procrear sino crear, por no golpear mujeres, por no matar jotitos, por no saber manejar o andar en bicicleta, por negarme a reproducir sus sistemas de control sobre mi cuerpo y la vida. Por ser antagonista, anti-héroe, escoger ser el fuego en lugar de Prometeo. Por ser la serpiente y no el águila. Ponzoñosa punzocortante (17).

En tanto adopta el tono y función de un manifiesto estético, el texto ofrece también orientaciones sobre la escenificación del cuerpo performático y particularmente del cuerpo del autor. Estas indicaciones escénicas son particularmente interesantes porque señalan al 
cuerpo como herramienta epistemológica que contribuye a des-biopolitizar la masculinidad para re-politizar el cuerpo:

Mi cuerpo es el arma más poderosa [...], la agencia Puñal comienza por penetrarse el recto con el mango de un cuchillo de carnicero, dando el culo al aire, rasgando el cielo, amenazante, y termina por navajearse el abdomen atlético, tenso, sangrante. Soy Puñal y herida. Penetrador y penetrable. Cuerpo lleno de bordes, de filos, de fisuras y de surcos. Una cartografía de suturas y cicatrices, paisaje de carne dividido por líneas imaginarias y táctiles, interseccional, transfronterizo, subalterno [...]; mi cuerpo vacío y sin órganos, mi cuerpo explícito, desollado. [...]. Porque la verdadera penetración es la que rasga el cuerpo, perfora el tejido y se clava donde no hay agujero. Soy Puñal por lo obsceno (en escena) de mis cortes y superficies sangrantes, porque soy "actor" (pos)porno, porque soy cuerpo atrapado en lo (caleidos)escópico (16-17).

El cuerpo enunciado textualmente, que luego va a ser expuesto en el espacio performático, es el cuerpo del subalterno mexicano des-masculinizado y des-heterosexualizado que toma la palabra, la encarna y se exhibe desde la abyección y la obscenidad, entendida ésta como lo que no hay que mostrar por considerarse, según la etimología del término, "fuera de escena". Es un cuerpo abierto, agrietado, herido, sin las fronteras o los límites impuestos al cuerpo masculino hegemónico; un cuerpo penetrador y penetrable que convierte la angustia masculina heteronormada de ser penetrado en estrategia de des-biopolitización. ¿En qué consiste esta des-biopolitización? Principalmente en poner el cuerpo - y "el culo"- estigmatizado en escena, si no con la pretensión de liberarlo completamente de las normas de la masculinidad, al menos sí para mostrar las grietas, tropiezos y fallos de su construcción biopolítica.

De cierto modo, el acto transgresor de exponer un cuerpo "obsceno" es un acto de revelación. Se trata de revelar lo que la biopolitización de los cuerpos ha dejado precisamente "fuera de escena". Si el arte performático admite un desarrollo político-discursivo como lo hace el texto "Pensamiento Puñal", grabado y difundido durante la presentación escénica, su esencia estética está en lo (audio)visual y en la puesta en escena del cuerpo del performancero.

\section{Crear (desde) el espacio performático}

La videograbación de la versión 2012 de la performance Pensamiento Puñal, disponible íntegramente en internet (aunque no provoca las mismas reacciones y apreciaciones que el acto en vivo, ya que recurre a las codificaciones del lenguaje fílmico), informa, no 
INVESTIGACIÓNTEATRAL

Revista de artes escénicas y performatividad

Vol. 9, Núm. 13

abril-septiembre 2018
Cuerpo estigmatizado y enunciación paratópica en la performance de Lechedevirgen Trimegisto

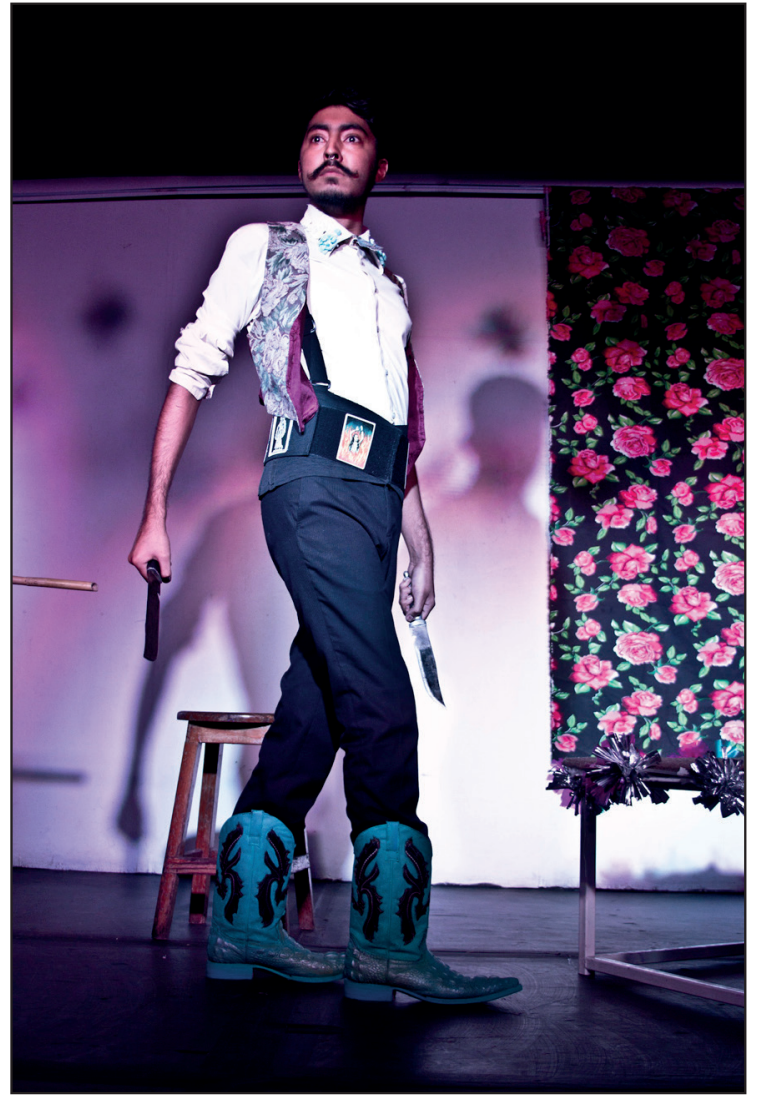

Antoine Rodríguez
Lechedevirgen Trimegisto en el performance Pensamiento Puñal. Festival Internacional de Performance "Extra!", Centro Cultural Xavier Villaurrutia. Ciudad de México, 2013. Fotografía de Herani Enríquez Amaya "HacHe”.

obstante, sobre las elecciones escenográficas y la gestión del cuerpo en el espacio performático (las imágenes incluidas aquí son de una presentación realizada en 2013). Lo primero que llama la atención es la importancia que el artista concede a los numerosos elementos escenográficos y a la banda de sonido omnipresente durante toda la performance. Sería imposible mencionar todos los elementos en el marco de este trabajo, así que elegiré solamente algunos que resultan pertinentes para dar cuenta tanto de la polisemia que brota de la obra, como de la empresa de deconstrucción a la que se dedica el artista.

La performance comienza con un sonido de helicóptero o de temblor. En el espacio escénico se puede ver una especie de telón de fondo negro con impresiones de rosas que recuerda a los manteles populares. Lechedevirgen entra: lleva bigote, pantalones negros de piel, botas vaqueras verdes, camisa blanca, chaleco de flores y una especie de cinturón-faja con cartas del tarot. En la frente, sobre la parte superior de las cejas, lleva clavadas algunas agujas de jeringas, y a manera de cetro ostenta un caballito de palo, el juguete infantil 
INVESTIGACIÓNTEATRAL

Revista de artes escénicas y performatividad

Vol. 9, Núm. 13

abril-septiembre 2018
Cuerpo estigmatizado y enunciación paratópica en la performance de Lechedevirgen Trimegisto

Antoine Rodríguez

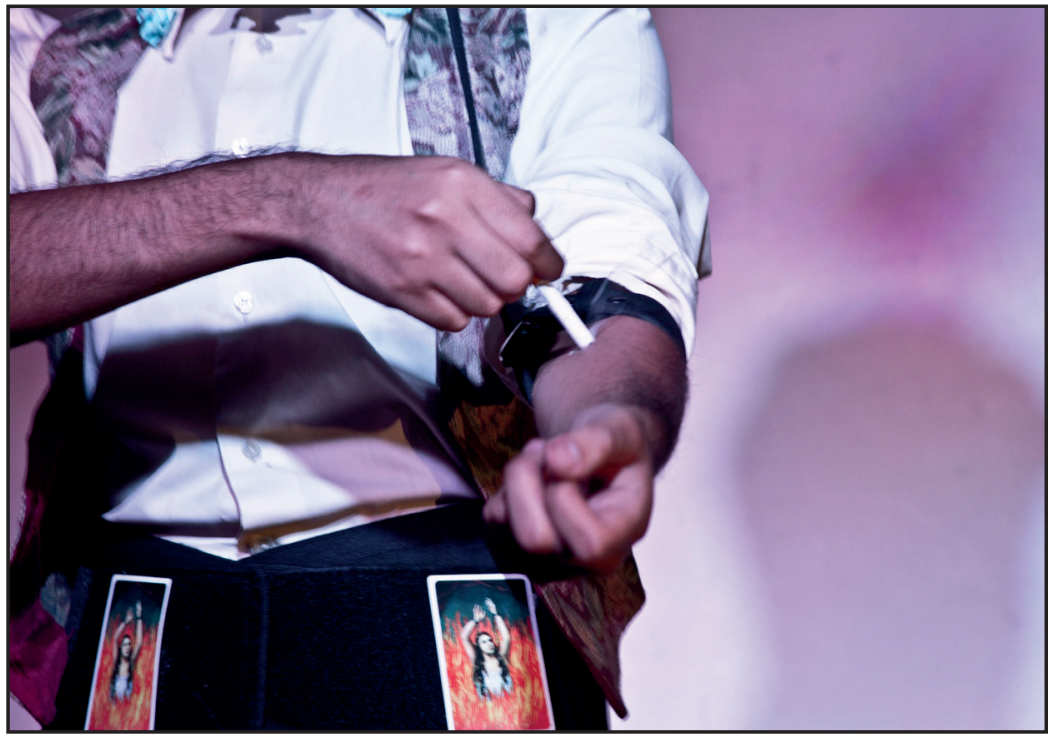

Lechedevirgen Trimegisto en el performance Pensamiento Puñal. Ciudad de México, 2013. Fotografía de Herani Enríquez Amaya "HacHe".

típico. Todos estos elementos van configurando un universo kitsch que no sólo posibilita un distanciamiento lúdico, sino además ejerce una fuerza estética seductora. No estamos en presencia de un hombre "hecho y derecho", sino de un individuo que acarrea algunos elementos de un simulacro de la masculinidad hegemónica. Éstos se mezclan, contradicen y contaminan paródicamente (por ejemplo, el bigote prototípico de virilidad se convierte en señal paródica). La parodia es, de hecho, una de las estrategias a las que recurre el performancero para des-biopolitizar la masculinidad hegemónica.

Otro proceso estético al que recurre Lechedevirgen es la construcción metafórica. Consiste en asociar dos o más elementos que en la realidad pertenecen a categorías diferentes, dotándolos de nuevos significados sin alterar el o los significantes de origen. Pondré dos ejemplos para ilustrarlo:

El performer se sienta, toma un cinturón con el que se ata un brazo como si fuera una goma de extracción de sangre. Enciende un cigarro, lo manipula como si se tratara de una jeringa y se lo clava encendido en el brazo. El cigarro es metafóricamente una jeringa, pero en esta transformación no ha dejado de ser un cigarro encendido. La metáfora convoca, por lo menos, dos imágenes y dos sensaciones: la jeringa que se clava en el brazo y la quemadura del cigarro; dos percepciones cuyo efecto refuerza la sensación de dolor. A su vez, otras imágenes posiblemente connotadas se superponen a esas: por ejemplo, escenas de tortura o violencia física. La metáfora funciona como un proceso de creación de imágenes y sensaciones polisémicas, polifónicas y enigmáticas que abren en el receptor múltiples interpretaciones y conexiones mentales. 
INVESTIGACIÓNTEATRAL

Revista de artes escénicas y performatividad

Vol. 9, Núm. 13

abril-septiembre 2018
Cuerpo estigmatizado y enunciación paratópica en la performance de Lechedevirgen Trimegisto

Antoine Rodríguez

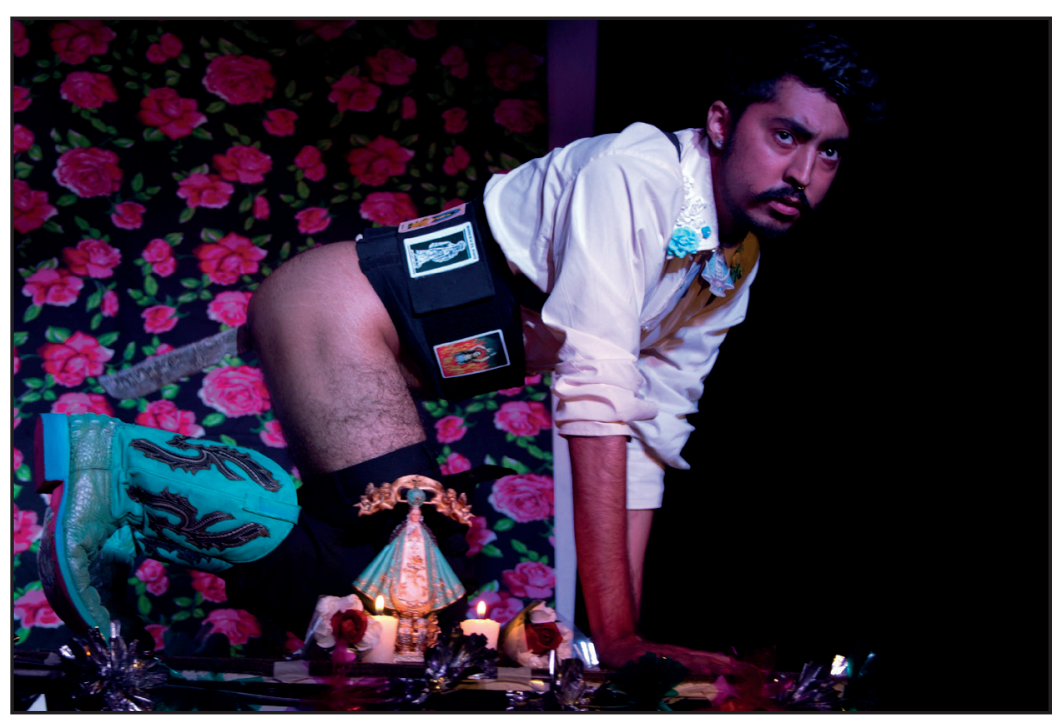

Performance Pensamiento Puñal. Ciudad de México, 2013. Fotografía de Herani Enríquez Amaya "HacHe".

El segundo ejemplo corresponde a otra secuencia en la que Lechedevirgen se introduce el mango de un puñal en el ano. El puñal que, como ya vimos, es también un sinónimo despectivo de homosexual, se convierte metafóricamente en pene erecto o dildo y remite a la sodomía, el tristemente famoso pecado nefando o contra natura, estigmatizado y condenado por la Santa Inquisición. Pero el objeto puñal no deja de ser tal, convocando las imágenes de herida o muerte que culturalmente se le asocian. Eros y Tanatos se reúnen de este modo en un mismo significante, que tiene la capacidad de convocar otros significados en asociación con el texto que se escucha en ese momento ("arma revolucionaria", "rifle en el ano en honor a Zapata", "goce sexual", "porno mariachi”). La imagen "extrema" de la sodomía efectuada en escena con un puñal pertenece al registro de lo habitualmente obsceno. Viene a perturbar no sólo las imágenes relacionadas con la masculinidad heteronormada, sino también las imágenes convencionales de una homosexualidad hegemónica que se practica en la intimidad o en espacios fuera de escena.

Pero quizá la secuencia más emblemática en cuanto al cuestionamiento estético de la masculinidad falocéntrica, sea aquella en la que Lechedevirgen, sentado en un taburete frente al público, simula cortarse los testículos con un puñal. ${ }^{9}$ La banda de sonido que

9 En 2010, el performer y filósofo puertorriqueño Bernat Tort, presentó un performance, On ne naît pas femme, on le devient, en el que se cubrió el rostro como mujer islámica y realizó con unas tijeras tres incisiones detrás de sus testículos. Con la sangre marcó tres páginas de los tres principales libros religiosos: el Corán, La Biblia y La Torá (Elnuevodia.com, "Habitar el cuerpo"). 
INVESTIGACIÓNTEATRAL

Revista de artes escénicas y performatividad

Vol. 9, Núm. 13

abril-septiembre 2018
Cuerpo estigmatizado y enunciación paratópica en la performance de Lechedevirgen Trimegisto

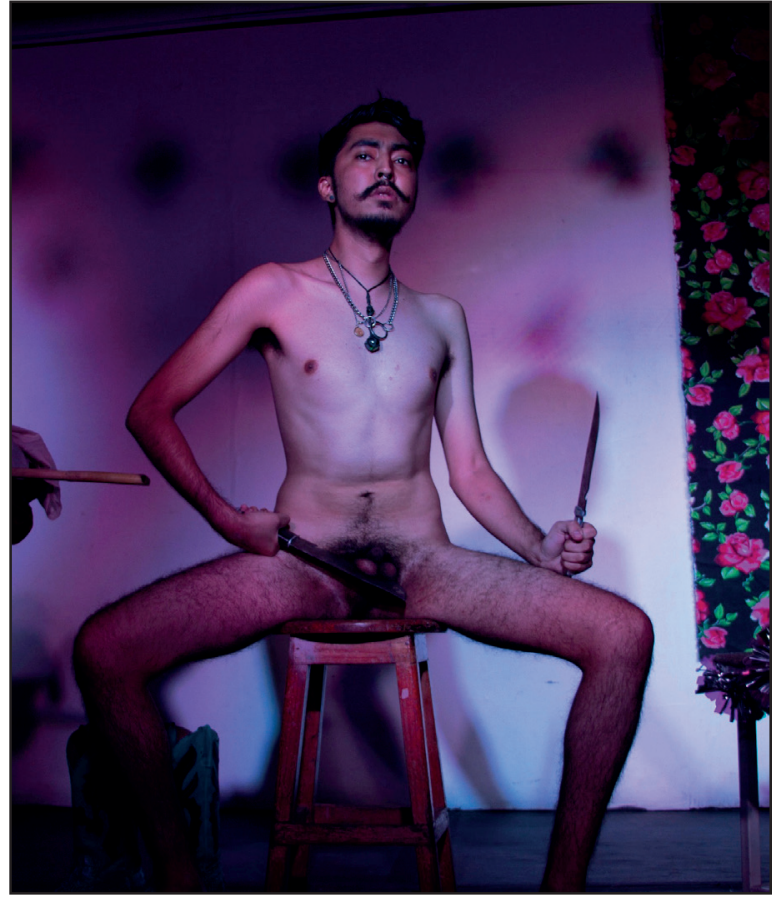

Performance Pensamiento

Puñal. Ciudad de México,

2013. Fotografía de Herani

Enríquez Amaya “HacHe”.

acompaña la escena va difundiendo un fragmento del texto "Pensamiento Puñal", cuya función es la de connotar las acciones, objetos y órganos exhibidos, en el proceso de significación metafórica ya aludido:

En el tarot las espadas simbolizan el lenguaje y el pensamiento, se trata pues de afilarse. No se trata de nombrarse Puñal, se trata de aPUÑALar, de volverse verbo, porque ante todo Puñal es acción en el mundo. Puñal no se conforma con la apropiación de la injuria, va más allá. Puñal se trata de un arma de doble filo, al tiempo que te haces daño, les haces daño [...]; se trata de afilarse cada borde del cuerpo, de ser repetitivo porque sólo así se saca el filo (19).

A partir de los significantes visuales (puñal, testículos, pene) la escena convoca y provoca varias imágenes y reacciones. Primero, una respuesta física, sensación dolorosa en el receptor, a la que le sigue una interpretación inmediata del acto de emasculación simulado. Cortarse los testículos viene a significar una voluntad de deshacerse del órgano que simboliza socialmente a la virilidad. Herirse es una manera de herir también al otro, o dicho de otro modo, deconstruir su propia masculinidad es una manera de deconstruir la masculinidad del otro. Pero en seguida el texto orienta la interpretación 
INVESTIGACIÓNTEATRAL

Revista de artes escénicas y performatividad

Vol. 9, Núm. 13

abril-septiembre 2018
Cuerpo estigmatizado y enunciación paratópica en la performance de Lechedevirgen Trimegisto

Antoine Rodríguez

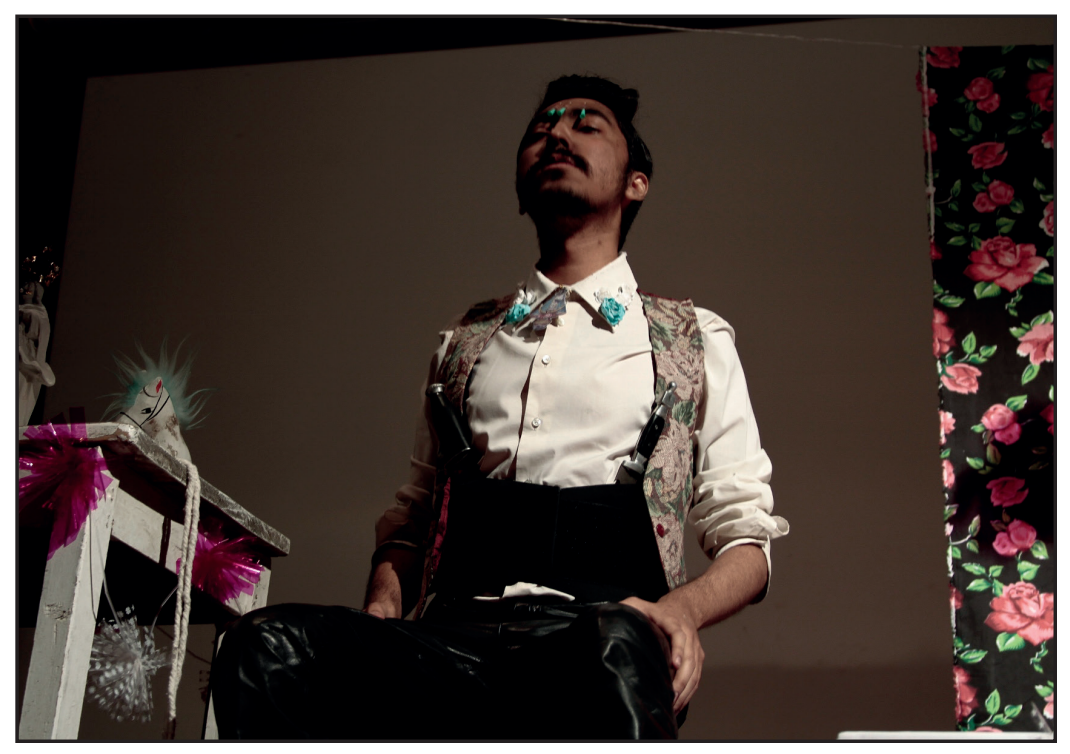

Performance Pensamiento

Puñal. Ciudad de México, 2013. Fotografía de Herani Enríquez Amaya "HacHe".

hacia niveles abstractos: el puñal pasa a ser metáfora de la espada que en el tarot simboliza al lenguaje. Ya no se trata, como habíamos leído en primera instancia, de cortarse los testículos sino de "afilarse" en el doble sentido de la palabra: sacar filo y aguzar el entendimiento. Se trata de cuestionar el lenguaje, portador de pensamiento, apropiándoselo y usándolo como arma de resistencia contra las construcciones simbólicas de una masculinidad coercitiva.

Podría multiplicar los ejemplos que ilustran las posturas estéticas de Lechedevirgen sin conseguir jamás abarcar las numerosas redes polisémicas de la obra. Es lo que hace de sus propuestas performáticas procesos creativos interesantes y fascinantes. Los cuestionamientos epistemológicos en torno a las normas de construcción del sistema de género y de la masculinidad en particular, se dan a través de la creación de imágenes que van más allá de una exposición discursiva. Convocan universos estéticos e imaginarios que tienen la capacidad de conectarse con las tramas y los traumas inconscientes del espectador, provocando fuerte adhesión o rechazo, pero también preguntas perturbadoras.

\section{Conclusión}

Felipe Osornio, alias Lechedevirgen Trimegisto, nace en 1991, al mismo tiempo que la incipiente teoría queer "blanca", introducida por Teresa de Lauretis ("Queer theory: Lesbian and Gay Sexualities"), Eve Kosofsky Sedgwick (Epistemogía del armario) y Judith Butler 
(El género en disputa). La teoría queer y los procesos de deconstrucción de las categorías identitarias relativas al sexo y al género, desestabilizan la naturalización de la sexualidad heterocéntrica, contribuyendo paralelamente a crear, dentro de las ciencias sociales, una especie de micro-episteme o marco epistémico que posibilita - y de cierto modo legitima- la emergencia de expresiones artísticas de inconformidad respecto a la formación de cuerpos valorados y prestigiados desde criterios hegemónicos de belleza, raza, clase o sexualidad. Lechedevirgen se inscribe en este movimiento teórico de deconstrucción, pero también se inspira en los textos teóricos del feminismo del Tercer Mundo estadounidense, tales como Borderlands / La Frontera de Gloria Anzaldúa, This Bridge Called My Back de Cherrie Moraga y Gloria Anzaldúa, o los textos de la chicana Chela Sandoval ("Feminismo cyborg"). Éstos ofrecen, desde antes de la teorización queer de los noventa, una reflexión sobre la situación de las mujeres de color atrapadas en redes de dominación debido no sólo a su género sino también a su clase social, orientación sexual y rasgos étnicos.

Lechedevirgen articula estos aportes teóricos con su inscripción artística en movimientos como el arte extremo (por ejemplo), que se vuelca a exhibir cuerpos y situaciones fuera de las consideraciones tradicionales de las bellas artes: cuerpos feos, deformados, heridos, enfermos, agónicos, monstruosos; prácticas obscenas, repugnantes o al límite de lo aguantable. El objetivo implícito parece ser, como lo mencionamos más arriba, el de des-biopolitizar la formación de los cuerpos prestigiados socialmente, para abrir espacio a aquellos que durante siglos han quedado fuera de escena por ser precisamente considerados "ob-scenos". Se trata de buscar un empoderamiento desde los márgenes, desde el cuerpo estigmatizado y herido, e incluso desde la obscenidad grotesca a la que da lugar también el ejercicio del biopoder.

Heredero de un arte performático "mexicano" como el del chicano Guillermo Gómez-Peña, cuyas performances interrogan los mitos del macho intercultural, o el de Rocío Boliver "La congelada de uva", basado en una combinación de prácticas porno-obscenas y profanaciones religiosas, Lechedevirgen es también creador de filiaciones a través de los talleres que imparte sobre cuerpo y performance. Receptor y emisor de prácticas artísticas que sacuden los binarismos del sistema sexo/género y los "grandes" relatos sobre raza y nación, este artista dedica su energía vital a cuestionar incansablemente los códigos convencionales de la masculinidad. Interrogar al género, al nacionalismo, a la clase y a la raza desde un cuerpo de subalterno estigmatizado, parece ser la única manera de hacer arte en la época contemporánea, quizás porque urge que emerja de las cenizas de un difunto cuerpo des-politizado, el nuevo sujeto queer post-identitario, una nueva ficción que aún no ha acabado de rascar ni de borrar la tinta del antiguo palimpsesto decimonónico en el que se escribieron parcialmente las reglas coercitivas del género. 


\section{Bibliografía}

Agamben, Giorgio. Homo sacer I. El poder soberano y la nuda vida. Trad. Antonio Gimeno. Valencia: Pre-Textos, 2010.

Anzaldúa, Gloria. Borderlands/ La Frontera. San Francisco: Aunt Lute Books, 1987.

Butler, Judith. El género en disputa. El feminismo y la subversión de la identidad. Barcelona: Paidós, 2007.

De Lauretis, Teresa. "Queer Theory: Lesbian and Gay Sexualities". Differences: a Journal of Feminist Cultural Studies, vol 3, núm. 2, 1991, pp. III-XVII.

Elnuevodia.com. "Habitar el cuerpo". El nuevo día, 20 de abril de 2010, en línea. Consultado el 27 de enero de 2018.

Foucault, Michel. "Des espaces autres". Architecture, Mouvement, Continuité, núm. 5, 1984, pp. 46-49.

Foucault, Michel. Histoire de la sexualité I - La volonté de savoir. Paris: Gallimard, 1976.

Goffman, Erving. Stigmate, les usages sociaux des handicaps. Paris: Les Editons de Minuit, 1975.

Gómez-Peña, Guillermo. "En defensa del arte del performance". Estudios avanzados de performance. Eds. Diana Taylor y Marcela Fuentes. México: Fondo de Cultura Económica, 2011, pp. 493-520.

Kosofsky Sedgwick, Eve. Epistemología del armario. Barcelona: Ediciones de la Tempestad, 1998.

Lanuza, Fernado R. y Raúl M. Carrasco, comps. Queer \& Cuir. Políticas de lo irreal. Querétaro: Fontamara, 2015.

Lechedevirgen Trimegisto. "Pensamiento Puñal". Tramoya. Cuaderno de teatro, núm. 120, 2014, pp. 13-20.

Lechedevirgen Trimegisto. "Pensamiento Puñal". Vimeo, 2013, en línea. Consultado el 28 de septiembre de 2015.

Maingueneau, Dominique. "Quelques implications d'une démarche d'analyse du discours littéraire". Contextes, núm. 1, 2006, en línea. Consultado el 26 de septiembre de 2015.

Maingueneau, Dominique. Le discours littéraire: Paratopie et scène d'énonciation. París: Armand Colin, 2004.

Moraga, Cherrie y Gloria Anzaldúa, eds. This Bridge Called My Back: Writings by Radical Women of Color. New York: Kitchen Table: Women of Color Press, 1981.

Muñoz, José Esteban. "Introducción a la teoría de la desidentificación". Estudios avanzados de performance. Eds. Diana Taylor y Marcela Fuentes. México: Fondo de Cultura Económica, 2011, pp. 555-603. 
Muñoz, José Esteban. Desidentification: Queers of Color and the Performance of Politics. Minneapolis / London: University of Minnesota Press, 1999.

Osornio, Felipe. "Felipe Osornio 'Lechedevirgen Trimegisto"' - Entrevista”. YouTube, 20 de octubre de 2014, en línea. Consultado el 20 de octubre de 2014.

Osornio, Felipe. "Entrevista en compañía de Felipe Osornio - Lechedevirgen Trimegisto - Realizada por Andrea". Vimeo, 9 de octubre de 2013, en línea. Consultado el 9 de octubre de 2013.

Osornio, Felipe. "Pensamiento puñal, crítica directa a las 'coreografías' sociales". La Jornada Jalisco, 20 de diciembre de 2013, en línea. Consultado el 28 de septiembre de 2015.

Preciado, Beatriz. "Entrevista con Beatriz Preciado: Posporno/Excitación disidente". Entrevista con Parole de Queer. Parole de Queer, 2014, en línea. Consultado del 25 de abril de 2016.

Prieto Stambaugh, Antonio. "El eros politizado del performance sexo-diverso en México". Conjunto. Revista de teatro latinoamericano, núm. 181, 2016, pp. 36-44.

Prieto Stambaugh, Antonio. "Corporalidades políticas: representación, frontera y sexualidad en el performance mexicano". Estudios avanzados de performance. Eds. Diana Taylor y Marcela Fuentes. México: Fondo de Cultura Económica, 2011, pp. 609-628.

Rubin, Gayle. "L'économie politique du sexe: transactions sur les femmes et systèmes de sexe/genre". Les cahiers du CEDREF, núm. 7, 1998, en línea. Consultado el 28 de septiembre de 2015.

Sandoval, Chela. "Nuevas ciencias. Feminismo cyborg y metodología de los oprimidos". Otras inapropiables. Feminismos desde las fronteras. Hooks, bell et al. Madrid: Traficantes de sueños, 2004, pp. 81-106.

Taylor, Diana y Marcela Fuentes, eds. Estudios avanzados de performance. México: Fondo de Cultura Económica, 2011.

ToutVaBienTV. "Lechedevirgen Trimegisto". YouTube, 15 de noviembre de 2013, en línea. Consultado el 28 de septiembre de 2015. 